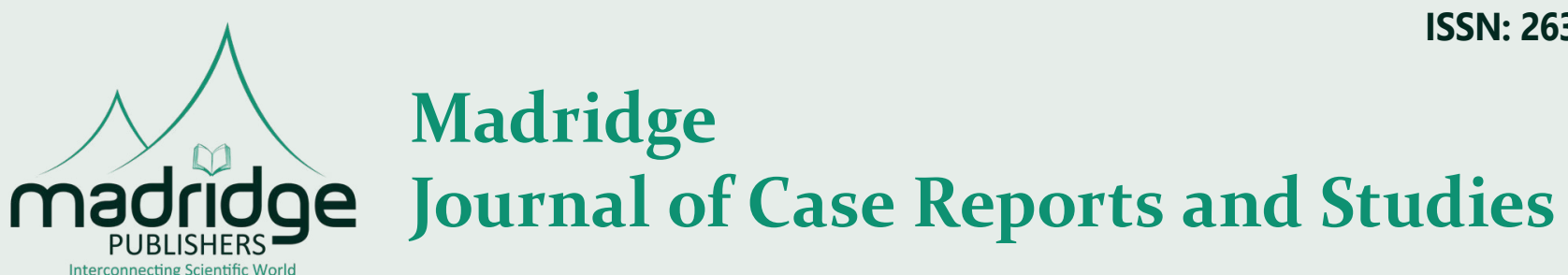

Case Series

Open Access

\title{
Variations in Intranasal Anatomical Parameters and Its Association with Rhinosinusitis - a One Year Hospital based Observational Study
}

\author{
Nitin R Ankle, Rajesh R Havaldar ${ }^{\star}$ and Samanvaya Soni \\ Department of ENT \& Head and Neck Surgery, J. N. Medical College, KLE Academy of Higher Education E Research, Belagavi, \\ Karnataka, India
}

\section{Article Info \\ *Corresponding author: \\ Rajesh R Havaldar \\ Senior Resident \\ Department of ENT \& Head and Neck Surgery \\ J. N. Medical College \\ KLE Academy of Higher Education \& \\ Research \\ Belagavi, Karnataka \\ India \\ E-mail: rajeshhavaldar@yahoo.com}

Received: November 11, 2019

Accepted: November 23, 2019

Published: November 29, 2019

Citation: Ankle NR, Havaldar RR, Soni S. Variations in Intranasal Anatomical Parameters and Its Association with Rhinosinusitis-a One Year Hospital based Observational Study. Madridge J Case Rep Stud. 2019; 4(1): 159-162.

doi: $10.18689 /$ mjcrs-1000142

Copyright: (c) 2019 The Author(s). This work is licensed under a Creative Commons Attribution 4.0 International License, which permits unrestricted use, distribution, and reproduction in any medium, provided the original work is properly cited.

Published by Madridge Publishers

\begin{abstract}
The lateral wall of the nose and the paranasal sinuses has intricate relationship with several adjacent structures such that anatomical variations are a very common entity. This urges the operating surgeon to tailor make the proposed endoscopic sinus surgery to every patient, in order to avoid inadvertent injuries and sequelae formation. The key areas being the anterior ethmoid which is the most susceptible for infection of the anterior group of sinuses and the sphenoethmoid recess for the posterior group of sinuses. Identification of these anatomical variations is the key for optimal disease clearance thus preventing morbidity associated with recurrence.
\end{abstract}

Keywords: Paranasal sinuses; Anatomical variations; Functional endoscopic sinus surgery.

\section{Introduction}

Few organs of the human body are liable to such remarkable interpersonal and intrapersonal variations as the paranasal sinuses. These pneumatic cavities are intertwined with neighboring structures in an intricate anatomical relationship which oftentimes leads to compromised ventilation and mucociliary clearance of the sinuses due to localized diseased mucosa or anatomic variations. The anterior ethmoid especially the infundibulum, is in a key location for infection, the disease in the frontal and maxillary sinuses is in fact, secondary to pathophysiologic changes in the infundibulum [1]. Similarly, mucociliary impairment in the sphenoethmoid recess, the drainage area of the posterior ethmoids and sphenoid is implicated in the etiology of persisting infection in the sinuses [2]. This study is designed to assess the role of various anatomical structures and their variations in causation of chronic rhinosinusitis on the basis of $\mathrm{CT}$ scan and intraoperative findings.

\section{Methods}

The present study is a one-year cross-sectional study done in KLE'S Dr. Prabhakar Kore Hospital and Research Centre, Belagavi, India. A total of 30 patients of chronic rhinosinusitis not responding to maximal medical therapy were included in the study. All the patients underwent diagnostic nasal endoscopy and computed tomography of nose and paranasal sinuses preoperatively. Further, functional endoscopic sinus surgery following the Messerklinger's technique was done on all the patients. It is to be noted that not all the steps were followed in each case as the extent of the surgery was tailored depending upon the preoperative evaluation and the extent of the disease. Out of 30 
patients, 20 needed bilateral surgery. Hence, a total of 50 procedures were performed. The extent of resection of the sphenoethmoid depended upon the pre and interoperative findings. Septal correction was done along with the endoscopic sinus surgery wherever indicated (7 cases). Anterior ethmoidectomy along with frontal recess clearance and middle meatal antrostomy was done in all 50 procedures while posterior ethmoidectomy was done in 47 and sphenoidotomy in 27 procedures. The parameters studied are osteomeatal complex with variations like agger nasi cells, Haller cells, variations of uncinate process, concha bullosa and accessory maxillary sinus ostium. Systematic examination of paranasal sinuses, frontal recess and sphenoethmoid recess was done and the mucosal changes and disease status was noted. For the correlation of the anatomical or pathological variations with the extent of disease in the sinuses, the statistical significance of each was calculated with the chisquare test using McNemar's formula (with Yate's correction wherever necessary). P value less than 0.05 meant that there was significant correlation between the parameters.

\section{Results}

The age of the patients varied from 21 to 53 years (mean 32.6 years) with majority being males in a male to female ratio of 1.7:1. Anterior ethmoidal sinus was the most frequently involved sinus with abnormal mucosa i.e. 42 out of the 60 sinuses. Followed by maxillary sinuses which had abnormal mucosa in 39 sinuses, then frontal recess i.e. 25 and lastly 14 sphenoid sinuses had abnormal mucosa (Figure 1). The agger nasi cells were present in 22 cases (73.33\%) where 20 were bilateral and 2 were unilateral agger nasi cells. An abnormally bent uncinate process, which included both the medialized and lateralized uncinate was present in 17 cases (56.66\%) out of them 15 were bilateral and 2 were unilateral. Concha bullosa was present in 9 cases (30\%) with 4 bilateral and 5 unilateral presentations. Figure 2 depicts the prevalence of various anatomical abnormalities noticed in the present study.

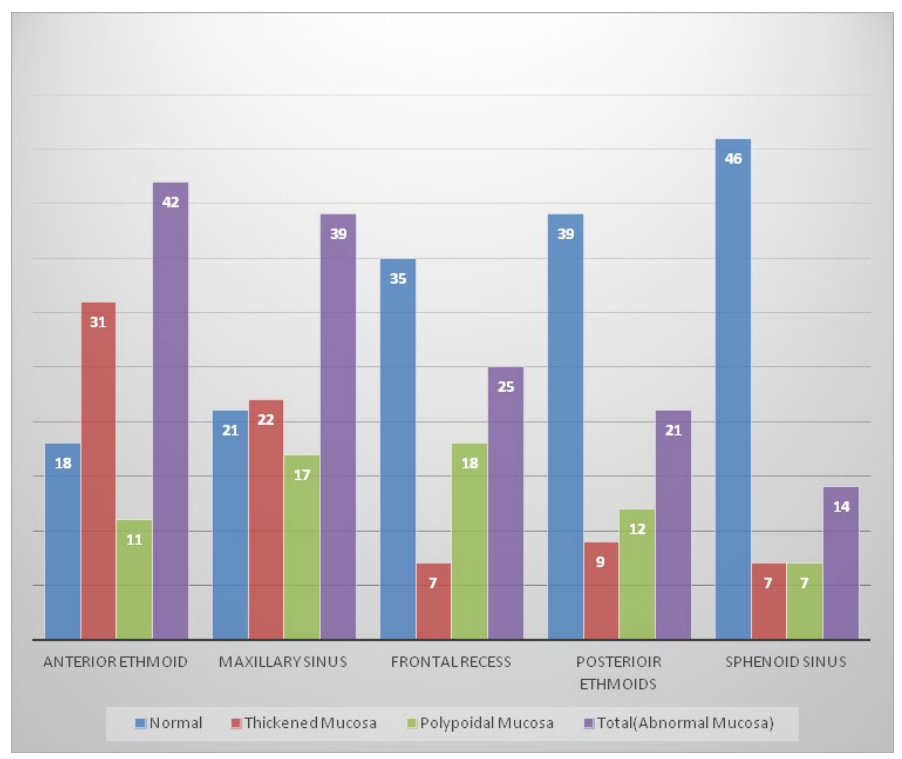

Figure 1. Mucosal Abnormalities in Various Sinuses at Operation.

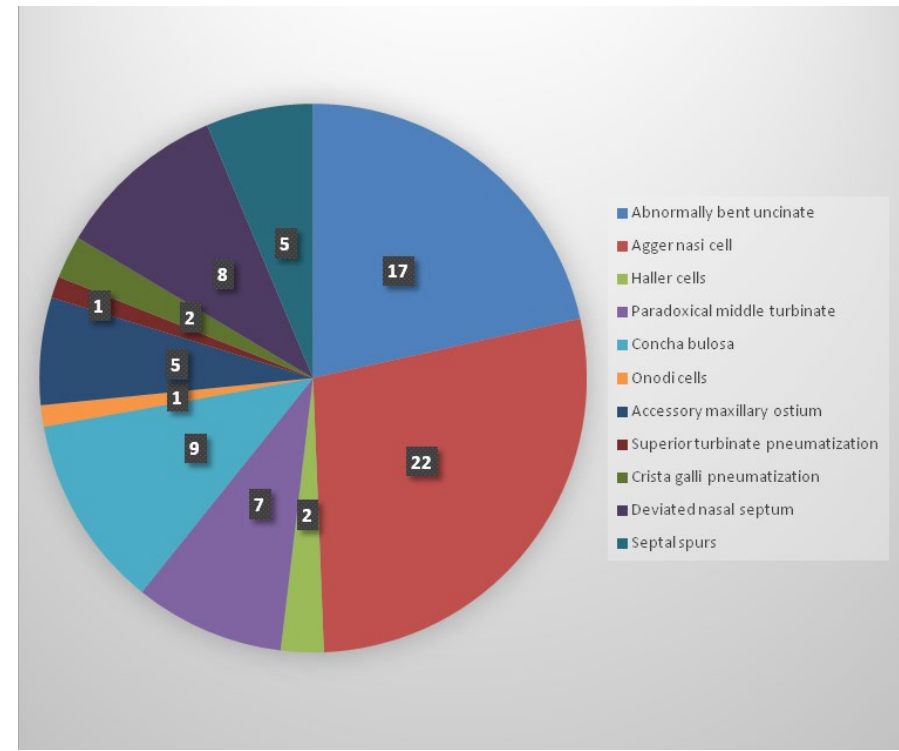

Figure 2. Prevalence of anatomical abnormalities in present study.

Presence of deviated nasal septum was not significantly correlated with the disease in any of the sinuses - anterior ethmoids $(p<0.09)$, maxillary sinus $(p>0.9)$, frontal recess ( $p>0.9)$, posterior ethmoids $(p>0.08)$ and sphenoid $(p>0.9)$.

In our study an abnormal uncinate correlated significantly with the disease in the anterior ethmoid and maxillary sinus $(p<0.05)$, but not with the disease in the frontal recess $(p>0.05)$.

The presence of agger nasi cells was significantly associated with the disease in all the anterior group of sinuses - anterior ethmoids $(p<0.001)$, maxillary sinus $(p<0.005)$ and frontal recess $(p<0.001)$.

Concha bullosa was significantly associated with the disease in anterior ethmoid $(p<0.001)$ and maxillary sinus $(p<0.001)$ but not with frontal recess $(p>0.05)$.

Paradoxical middle turbinate was significantly associated with the disease in the anterior group of sinuses - anterior ethmoids $(p<0.001)$, maxillary sinus $(p<0.001)$ and frontal recess $(p<0.005)$.

An abnormal infundibulum which included the partially occluded or totally occluded infundibulum, was significantly associated with the disease in anterior ethmoid $(p<0.005)$ and maxillary sinus $(p<0.01)$ but not with the frontal recess $(p>0.05)$.

An abnormal middle meatus, which included both the blocked and narrowed middle meatus, was significantly associated with the disease in the anterior ethmoid $(p<0.01)$ and maxillary sinus $(p<0.05)$ but not with the frontal recess $(p>0.5)$.

The disease in the anterior ethmoids or the infundibulum was significantly associated with the disease in frontal or maxillary sinuses $(p<0.005)$ (Table 1$)$.

Sphenoethmoid recess was significantly correlated with the disease in both the posterior ethmoids $(p<0.01)$ and sphenoid $(p<0.01)$ (Table 2$)$. 
Table 1. Relationship between anterior ethmoid or infundibular disease with maxillary or frontal sinus disease.

\begin{tabular}{|c|c|c|c|}
\hline $\begin{array}{c}\text { Anterior ethmoid or } \\
\text { infundibular disease }\end{array}$ & \multicolumn{3}{|c|}{ Frontal or Maxillary disease } \\
\hline & Present & Absent & Total \\
\hline Present & $37(88.09 \%)$ & $5(11.90 \%)$ & $42(70 \%)$ \\
\hline Absent & $5(27.77 \%)$ & $13(72.22 \%)$ & $18(30 \%)$ \\
\hline Total & $42(70 \%)$ & $18(30 \%)$ & $60(100 \%)$ \\
\hline Chi-square & & 10.58 \\
\hline P-value & & $\mathrm{P}<0.005$ \\
\hline
\end{tabular}

Table 2. Correlation of sphenoethmoid recess with posterior group of sinuses.

\begin{tabular}{|c|c|c|c|c|}
\hline $\begin{array}{c}\text { Sphenoethmoid } \\
\text { Recess }\end{array}$ & \multicolumn{2}{|c|}{ Posterior ethmoids } & \multicolumn{2}{c|}{ Sphenoid } \\
\hline & Diseased & Normal & Diseased & Normal \\
\hline Abnormal & $\begin{array}{c}16 \\
(94.11 \%)\end{array}$ & $\begin{array}{c}1 \\
(5.88 \%)\end{array}$ & $13(76.47 \%)$ & $4(23.52 \%)$ \\
\hline Normal & $\begin{array}{c}5 \\
(11.62 \%)\end{array}$ & $\begin{array}{c}38 \\
(88.37 \%)\end{array}$ & $1(2.32 \%)$ & $42(97.67 \%)$ \\
\hline Chi-square & \multicolumn{2}{|c|}{8.16} & \multicolumn{2}{c|}{14.25} \\
\hline p-value & \multicolumn{2}{|c|}{$P<0.01$} & \multicolumn{2}{c|}{$P<0.001$} \\
\hline
\end{tabular}

\section{Discussion}

In today's practice of chronic rhinosinusitis, it is mandatory that all the patients undergo diagnostic nasal endoscopy and CT scan of nose and paranasal sinuses preoperatively to evaluate the type of pathology, the extent of disease, and presence of anatomical abnormalities with special attention to the osteomeatal complex.

In the present study out of 30 patients, 20 underwent bilateral functional endoscopic sinus surgery, hence a total of 50 procedures were carried out. Abnormal mucosa was most frequently present in the anterior ethmoid (70\%) and maxillary sinuses (65\%) (Figure 1). Similar observations were made in a study done by Bolger et al. [3], where mucosal abnormalities were most frequently noted in the anterior ethmoids (78.2\%), followed by maxillary $(68.8 \%)$, frontal $(30.5 \%)$, posterior ethmoid (32.2\%) and sphenoid (22.3\%). These data coincide with those reported in the study by Kennedy et al. [4], who also noted the anterior ethmoid to be the most frequently involved area of the paranasal sinus.

Anatomical variations of normal paranasal sinus structures may predispose patient to recurrent rhinosinusitis and in selected cases to headaches. Stammberger and Wolf [5] cited variations in the agger nasi cell, middle turbinate, uncinate process as well as the presence of Haller cells or a deviated nasal septum as a possible cause for rhinosinusitis and headache. In the present study one or more anatomic variations were observed in $76.66 \%$ of the cases as compared to $64.9 \%$ reported by Bolger et al. [3], $62 \%$ by Zinreich [6], and 79\% by S.P.S. Yadav [7] (Table 3, [8-17]).

The commonest variant in the study was agger nasi cell (73.33\%) which was similar to the findings of Bolger et al. [3] and Jones NS [8] in whom agger nasi cells were present in 98.5\% and $95 \%$ cases respectively. However the study done by Aramani et al. [15] reported the commonest anatomical variation to be deviated nasal septum $(74.10 \%)$, concha bullosa (53.70\%) as opposed to agger nasi which was seen in only $1.90 \%$ cases.

The prevalence of deviated nasal septum in our study was $26.66 \%$ as compared to the prevalence reported by Calhom et al. [9] i.e. about $40 \%$ and $96.9 \%$ by Takanishi et al. [10]. In our study $56.6 \%$ cases showed the presence of an abnormal uncinate. The variations of the uncinate process are medially turned uncinate, laterally turned uncinate, anteriorly bent uncinate, uncinate bulla and fracture of uncinate.

The relationship between anterior ethmoid disease and chronic rhinosinusitis has been recognized for many years $[11,12]$. The frontal and the maxillary sinuses drain into the middle meatus. Their openings in the middle meatus, are surrounded by the frontal recess and ethmoid infundibulum respectively both of which form a part of the anterior ethmoid complex. Thus, in effect these sinuses drain into the middle meatus via the anterior ethmoids. This anatomical feature explains why disease in anterior ethmoids leads to persistent infection of the dependent sinuses.

Table 3. Anatomical abnormalities: comparison of various studies.

\begin{tabular}{|c|c|c|c|c|c|c|c|c|}
\hline Anatomical abnormalities & Present study & $\begin{array}{l}\text { Jones NS et. } \\
\text { al. [8] }\end{array}$ & $\begin{array}{l}\text { SPS Yadav et } \\
\text { al. [7] }\end{array}$ & $\begin{array}{l}\text { Bolger et al. } \\
\text { [3] }\end{array}$ & $\begin{array}{c}\text { Talaiepour AR et } \\
\text { al. [13] }\end{array}$ & $\begin{array}{l}\text { Dua K et al. } \\
\text { [14] }\end{array}$ & $\begin{array}{l}\text { Aramani A et } \\
\text { al. [15] }\end{array}$ & $\begin{array}{l}\text { Mamatha H et } \\
\text { al. [16] }\end{array}$ \\
\hline Agger nasi cells & $73.33 \%$ & $95.00 \%$ & $48.00 \%$ & $98.50 \%$ & $56.70 \%$ & $40.00 \%$ & $1.90 \%$ & $50.00 \%$ \\
\hline Haller cells & $6.66 \%$ & $6.00 \%$ & $28.00 \%$ & $45.10 \%$ & $3.50 \%$ & $16.00 \%$ & $1.90 \%$ & $17.50 \%$ \\
\hline Abnormal uncinate & $56.66 \%$ & $6.00 \%$ & & & & $6.00 \%$ & $14.80 \%$ & $65.00 \%$ \\
\hline $\begin{array}{l}\text { Paradoxical midle } \\
\text { turbinate }\end{array}$ & $23.33 \%$ & $7.00 \%$ & $12.00 \%$ & $26.10 \%$ & & $10.00 \%$ & $14.80 \%$ & \\
\hline Concha bullosa & $30.00 \%$ & $18.00 \%$ & $28.00 \%$ & $55.00 \%$ & $35.00 \%$ & $16.00 \%$ & $53.70 \%$ & $15.00 \%$ \\
\hline Onodi cells & $3.33 \%$ & $7.00 \%$ & & & $7.00 \%$ & $6.00 \%$ & & \\
\hline $\begin{array}{c}\text { Accessory maxillary } \\
\text { ostium }\end{array}$ & $16.66 \%$ & & & & & & & \\
\hline Deviated nasal septum & $26.66 \%$ & $24.00 \%$ & $38.00 \%$ & $40.00 \%$ & $63.00 \%$ & $44.00 \%$ & $74.10 \%$ & $65.00 \%$ \\
\hline $\begin{array}{l}\text { Superior turbinate } \\
\text { pneumatization }\end{array}$ & $3.33 \%$ & & & & & & & \\
\hline $\begin{array}{c}\text { Crista Galli } \\
\text { pneumatization }\end{array}$ & $6.66 \%$ & & & & & & & \\
\hline
\end{tabular}


Our data supports this relationship, in that $88.09 \%$ of patients with mucosal abnormalities located in the anterior ethmoids or infundibulum were found to have disease in the ipsilateral frontal and maxillary sinuses. Conversely, the absence of disease in these regions correlated highly with normal frontal and maxillary sinuses $(p<0.005)$ (Table 1$)$.

A narrow or blocked sphenoethmoid recess can block the drainage of the posterior ethmoid and sphenoid sinuses. As shown in table 2, in present study the correlation of an abnormal sphenoethmoid recess was statistically significant for both posterior ethmoid $(p<0.001)$ and sphenoid sinuses $(p<0.01)$. Total of $94.11 \%$ of posterior ethmoids and $76.47 \%$ of sphenoid sinus were diseased in the presence of an abnormal sphenoethmoid recess (Table 2).

\section{Conclusion}

The osteomeatal complex shows a diverse anatomic variation with the presence of agger nasi cells, Haller cells, abnormalities of uncinate, concha bullosa etc. which leads to disease in anterior ethmoids and infundibulum. Identification of these anatomical variations and addressing them during surgery is key to attain optimal disease clearance. The association of anterior ethmoid disease as a conduit to ipsilateral frontal and maxillary sinus disease and the role of sphenoethmoid recess in causing disease of posterior group of sinuses have been positively established with this study and the need to achieve adequate clearance of disease from these key areas is emphasized.

\section{Conflicts of Interest Statement}

The authors hereby declare no conflicts of interest in the present study.

\section{References}

1. Becker SP. Applied anatomy of the paranasal sinuses with emphasis on endoscopic surgery. Ann Otol Rhinol Laryngol Suppl. 1994; 162: 3-32.

2. Davis WE, Templer J, Parsons DS. Anatomy of the paranasal sinuses. Otolaryngol Clin North Am. 1996; 29(1): 57-74.

3. Bolger WE, Butzin CA, Parsons DS. Paranasal sinus bony anatomic variations and mucosal abnormalities: $\mathrm{CT}$ analysis for endoscopic sinus surgery. Laryngoscope. 1991; 101: 56-64. doi: 10.1288/00005537199101000-00010
4. Kennedy DW, Zinreich SJ, Shaalan $\mathrm{H}$, et al. Endoscopic middle meatal antrostomy, theory, technique and patency. Laryngoscope. 1987; 97: 1-9. doi: 10.1288/00005537-198708002-00001

5. Stammberger $\mathrm{H}$, Wolf $\mathrm{G}$. Headaches and sinus disease: the endoscopic approach. Ann Otol Rhinol Laryngol Suppl. 1988; 134: 2-23. doi: 10.1177/00034894880970s501

6. Zinreich SJ, Kennedy DW, Rosenbaum AE, Gayler BW, Kumar AJ, Stammberger $\mathrm{H}$. Paranasal sinuses: CT imaging requirements for endoscopic surgery. Radiology. 1987; 163(3): 769-775. doi: 10.1148/ radiology.163.3.3575731

7. Asruddin, Yadav SP, Yadav RK, Singh J. Low dose CT in chronic sinusitis. Indian J Otolaryngol Head Neck Surg. 1999; 52(1): 17-22. doi: 10.1007/ BF02996425

8. Jones S, StroblA, Holland I. A study of the CT findings in 100 patients with rhinosinusitis and 100 controls. Clin Otolaryngol Allied Sci. 1997; 22(1): 47-51. doi: 10.1046/j.1365-2273.1997.00862.x

9. Calhoun $\mathrm{KH}$, Rotzler $\mathrm{WH}$, Stiernberg $\mathrm{CM}$. Surgical anatomy of the lateral nasal wall. Otolaryngol Head Neck Surg. 1990; 102(2): 156-160. doi: $10.1177 / 019459989010200210$

10. Takanishi R. The formation of the nasal septum and the aetiology of septal deformity. The concept of evolutionary paradox. Acta Otolaryngol Suppl. 1987; 443: 1-160.

11. Stammberger $\mathrm{H}$. An endoscopic study of tubal function and the diseased ethmoid sinus. Arch Otorhinolaryngol. 1986, 243: 254-259. doi: 10.1007/bf00464441

12. Kennedy DW, Zinreich SJ, Rosenbaum AE, Johns ME. Functional endoscopic sinus surgery. Theory and diagnostic evaluation. Arch Otolaryngol. 1985; 111(9): 576-582.

13. Kennedy DW. Functional endoscopic sinus surgery. Technique. Arch Otolaryngol. 1985; 111(10): 643-649.

14. Talaiepour AR, Sazgar AA, Bagheri A. Anatomic variations of the paranasal sinuses on CT scan images. Front Dent. 2005; 2(4): 142-146.

15. Dua K, Chopra H, Khurana AS, Munjal M. CT-scan variations in chronic sinusitis. IJRI. 2005; 15(3): 315-320.

16. Aramani A, Karadi RN, Kumar S. A Study of Anatomical Variations of Osteomeatal Complex in Chronic Rhinosinusitis Patients-CT Findings. J Clin Diagn Res. 2014; 8(10): KC01-KC04. doi: 10.7860/ JCDR/2014/9323.4923

17. Mamatha $H$, Shamasundar NM, Bharathi MB, Prasanna LC. Variations of ostiomeatal complex and its applied anatomy: a CT scan study. Indian J Sci Technol. 2010; 3(8): 904-907. doi: 10.17485/ijst/2010/ v3i8/29907 